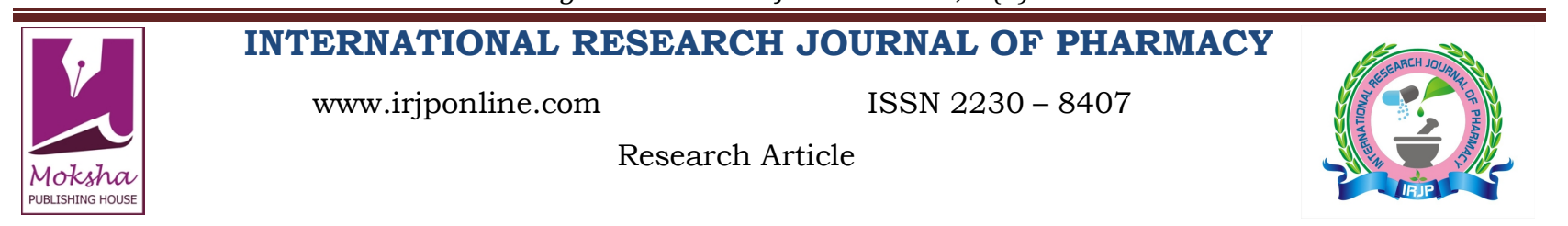

\title{
A ROLE OF APATYAKARA GHRITA (AN AYURVEDIC FORMULATION) IN MANAGEMENT OF OLIGOZOOSPERMIA
}

\author{
Bagde A. B.* \\ Assistant Professor, Dept. of Sanskrit samhita siddhant, Govt. Ayurved College, Osmanabad, M.S., India \\ Email: drabbagde@yahoo.co.in
}

Article Received on: 13/01/13 Revised on: 01/02/13 Approved for publication: 01/03/13

DOI: $10.7897 / 2230-8407.04325$

IRJP is an official publication of Moksha Publishing House. Website: www.mokshaph.com

(C) All rights reserved.

\begin{abstract}
Infertility as a medical and social problem has acquired global dimensions and its incidence is supposed to be gradually increasing by every decade. Despite great advances made by medical science in understanding each stage of the reproductive process, the problems that occur at each step and planning their management, some arenas post lacunae, due to which infertility is still a catastrophe. One such arena is the role of Oligozoospermia in male infertility and its management. The present study was undertaken to understand the role of Apatyakara Ghrita (an Ayurvedic formulation) in male infertility i.e. Oligozoospermia. Individuals $(\mathrm{N}=20)$, whose semen sample was having low sperm count $<20 \mathrm{millions} / \mathrm{ml}$ and $\mathrm{motility}<50 \% \mathrm{SLP},<25 \%$ RLP (WHO1992) were selected from the O.P.D. The selected patients were given Apatyakara Ghrita - 10 g twice a day with lukewarm milk for 90 days. After analyzing semen reports before and after treatment, suggested a definite role of Apatyakara Ghrita to treat infertility related with oligozoospermia. Treatment resulted $71.14 \%$ increase in sperm count which is statistically highly significant [ $<<0.001$ ], improved level motility by $79.05 \%$ $[\mathrm{p}<0.001]$ and improved overall semen quality in a significant number of individuals. There was an increase in sexual desire by $87.87 \%$ in patient which is statistically shows highly significant results. The penile erectile function was improved by $71.79 \%$ [p $<0.001$ ] in registered patient which shows highly significant results. There was $23.08 \%$ relief in Night emission and post act exhaustion was improved by $43.10 \%$. There is relief of $54.54 \%$ in dyspnoea on effort and $60.52 \%[\mathrm{p}<0.001]$ in pain after and during coitus which statistically highly significant.

Keywords: Oligospermia, Apatyakara Ghrita, Infertility, Oligozoospermia
\end{abstract}

\section{INTRODUCTION}

Infertility is defined as the inability of a couple to conceive after 12 months of unprotected regular sexual intercourse and it is estimated to affect $10 \%-15 \%$ of all couples. In almost half of such cases, a male factor is involved, but $15 \%-24 \%$ have unexplained etiology ${ }^{1}$. Most of the infertile men are reported to have a low sperm concentration and decreased motility as the cause. Alterations in spermatogenesis event may result in the release of immature or abnormal spermatozoa in the ejaculate. Although the total sperm count may still be within the normal fertile range these individuals may turn infertile due to large fraction of unfit spermatozoa ${ }^{2}$. Oligozoospermia, it termed as Ksheena Shukra in Ayurvedic texts which indicate low volume and less number of sperms in seminal fluid. In Oligozoospermia, the total spermatozoal count/ concentration will be less than 20 millions $/ \mathrm{ml}$. Cause of male infertility is Oligozoospermia which contributes to $13.94 \%{ }^{3}$.

Charaka has mentioned various drugs which are useful in the treatment of Alpa, Ksheena and Dushta Retas in his text Charaka Samhita which directly act on Shukra by Shukra Janana (inducing spermatogenesis) and Shukra Shodhana (cleansing of spermatozoa) properties. Apatyakara Ghrita is one of them ${ }^{4}$. Shukrala and Vrishya Karma are possessed by ingredients of Apatyakara Ghrita (80\%), whereas, $60 \%$ of ingredients are having Balya property. In the present study, an attempt was made to investigate role of Apatyakara Ghrita in infertile men in which cause of infertility was Oligozoospermia.

\section{Objective}

The primary objective of the study was to evaluate the efficacy of Apatyakara Ghrita in men having infertility w.s.r.t. Oligozoospermia.

\section{MATERIALS \& METHODS}

The study was an open-label, non-comparative, interventional, and exploratory clinical trial.

\section{Plant Material}

Dried herbs were collected from local market of Jaipur, Rajasthan. This raw material was authenticated in the Pharmacognosy Laboratory of NIA, jaipur.

\section{Preparation of Apatyakara Ghrita}

Before the preparation, Murchhana of Ghrita was done with Amalaki (Emblica officinalis), Bibhitaki (Teminalia bellirica), Haritaki (Teminalia chebula), Nagarmotha (Cyperus rotundus), Haridra (Curcuma longa), and Lime juice (Citrus media). Apatyakara Ghrita was prepared in pharmacy of National Institute of Ayurveda, Jaipur with the following ingredients ${ }^{4}$. [Table 1]

\section{Cow Ghee \& Milk}

Cow ghee \& milk was procured from Go-Shala attached to NIA, Jaipur.

\section{Water}

Potable tap water from the pharmacy of NIA, Jaipur was used to prepare kalka.

\section{Procedure}

The Apatyakara ghrita was prepared by adopting classical method according to need. Fine paste (Kalka) of ingredients was prepared and was spread evenly on the inner side of the bottom of a stainless steel container. Cow ghee in proportion to the paste, was slowly spread over the paste without disturbing it. Cow milk was mixed with the cow ghee in the container and thoroughly mixed without disturbing the paste spread at the bottom. The container was then placed on a gas burner and heating was started on a low to moderate flame as 
per the requirement. The contents were constantly stirred and heating was continued till half of the milk got evaporated, after which heating was discontinued and the contents were left to cool overnight. The heating was then resumed on the next morning observing the same precautions described above till all the water content in milk evaporated from the ghee. The contents were frequently tested for completion of the process and to decide the termination of heating. The heating was stopped as soon as the end point was reached. The container was then removed from the flame and left to cool on its own. The contents were filtered in warm condition through a muslin cloth. The filtrate i.e. Apatyakara ghrita was collected in a clean autoclaved glass bottle and weighed ${ }^{5}$.

Dose: 10 gm twice per day.

Anupana: Lukewarm water

\section{Sample Size Calculation}

Sample size calculation was based on the assumption that a sample size of 20 cases would provide a $90 \%$ power to detect mean change in frequency of growth per fortnight at $5 \%$ level of significance.

\section{Institutional Ethics Committee Approval and Regulatory Compliance}

Before the initiation of the study, the study protocol and related documents were reviewed and approved by Institutional Ethics Committee at NIA, Jaipur. The study was conducted in accordance with Schedule $\mathrm{Y}$ of Drugs and Cosmetics act, India, amended in 2005 and ICMR ethical guidelines for biomedical research on human participants $2006^{6}$.

\section{Gradation of Subjective parameters}

Sexual desire (Libido)
\begin{tabular}{|c|c|}
\hline Parameter & Score \\
\hline No desire at all & 0 \\
\hline Lack of desire & 1 \\
\hline Desire present but no activity & 2 \\
\hline Desire only on demand of partner & 3 \\
\hline Normal desire & 4 \\
\hline Excessive desire & 5 \\
\hline
\end{tabular}

\section{Penile Erection}

\begin{tabular}{|c|c|}
\hline Parameter & Score \\
\hline No erection by any method & 0 \\
\hline Erection possible only by artificial methods & 1 \\
\hline Erection but unable to penetrate. & 2 \\
\hline Initial difficulty but able to penetrate & 3 \\
\hline Erection with occasional failure & 4 \\
\hline Erection whenever desired & 5 \\
\hline
\end{tabular}

Night emission- Frequency

\begin{tabular}{|c|c|}
\hline Parameter & Score \\
\hline Nil & 0 \\
\hline Once a week & 1 \\
\hline Twice a week & 2 \\
\hline More than twice a week. & 3 \\
\hline
\end{tabular}

\section{Patients screening and recruitment}

Patients (age group, 25 to 40 years) attending the Outpatient Clinic at NIA, Jaipur, Rajasthan and meeting all the inclusion criteria were recruited in the trial

\section{Inclusion criteria}

- The semen samples which contain decreased semen count, Sperm quantity and Sperm motility as per WHO Criteria $^{3}$.

- The patients complaining of infertility were selected on the basis of subjective parameters of Ksheena Shukra ${ }^{7}$.

\section{Exclusion Criteria}

- Unmarried males \& male below age 20 \& above 40 years of age.

- Patients suffering from Azoospermia.

- Patients suffering with systemic diseases like Tuberculosis, Diabetes Mellitus, Cardiac disorders etc.

- Patients suffering from congenital reproductive system deformities.

- Patients suffering from sexually transmitted diseases.

\section{Study procedure}

At the screening visit, following written informed consent, patients were considered for study. Patients were assessed and evaluated on the basis of objective and subjective parameters at interval of 7 days for 90 days.

Objective parameters: Semen analysis - as per recommendations of W.H.O. (1992) manual.

Subjective parameters: Sexual desire (Libido), Penile Erection, Night emission- Frequency, Post act exhaustion (Daurbalya), Dyspnoea on effort, Pain after and during coitus

\begin{tabular}{|c|c|}
\hline Parameter & Score \\
\hline No exhaustion at all & 0 \\
\hline Slight exhaustion occasionally & 1 \\
\hline Exhausted in 25\% of the encounters. & 2 \\
\hline Exhausted in 50\% of the encounters. & 3 \\
\hline Exhaustion in 75\% sexual acts & 4 \\
\hline Exhaustion after every sexual encounter & 5 \\
\hline
\end{tabular}

Dyspnoea on effort

\begin{tabular}{|c|c|}
\hline Parameter & Score \\
\hline No discomfort / Dyspnoea. & 0 \\
\hline Mild dyspnoea on effort. & 1 \\
\hline Dyspnoea sometimes interrupting the sexual act. & 2 \\
\hline Dyspnoea during fore play. & 3 \\
\hline
\end{tabular}

Pain after and during coitus

\begin{tabular}{|c|c|}
\hline Parameter & Score \\
\hline No pain & 0 \\
\hline Some degree of discomfort. & 1 \\
\hline Pain at least half the time & 2 \\
\hline Pain after each sexual act. & 3 \\
\hline
\end{tabular}


Bagde A. B. Int. Res. J. Pharm. 2013, 4 (3)

Table 1 Ingredients of Apatyakara Ghrita

\begin{tabular}{|c|c|c|c|}
\hline Drug's Name & Latin Name & Quantity & Part Used \\
\hline Shatavari & Asparagus racemosus linn. & $30 \mathrm{Kg}$. & Tuber \\
\hline Kappikacchu & Mucuna prurita linn. & $30 \mathrm{Kg}$. & Seed \\
\hline Gokshura & Tribulus terrestris linn. & $30 \mathrm{Kg}$. & Seed \\
\hline Vidari & Pueraia tuberosa linn. & $30 \mathrm{Kg}$. & Tuber \\
\hline Black gram & Phaseolus mungo linn. & $30 \mathrm{Kg}$. & Seed \\
\hline Ghrita & Butryum departum linn. & $30 \mathrm{Kg}$. & --- \\
\hline Milk & --- & $240 \mathrm{Lit}$. & --- \\
\hline
\end{tabular}

Table 2 Pattern of Seminal Changes in 20 Subjects of Oligozoospermia [Ksheena Shukra] after Apatyakar Ghrita Therapy

\begin{tabular}{|c|c|c|c|c|c|c|c|c|}
\hline \multirow{2}{*}{ Semen Analysis } & \multicolumn{2}{|c|}{ Mean } & \multirow{2}{*}{ Mean Diff. } & Relief \% & S.D. & S.E. & t & p \\
\cline { 2 - 6 } & B.T. & A.T. & & & & & & \\
\hline Volume & 0.74 & 1.325 & 0.585 & 79.05 & 0.2488 & 0.0566 & 10 & $<0.001$ \\
\hline Sperm Count & 37.25 & 63.75 & 26.5 & 71.14 & 11.90 & 2.662 & 9.95 & $<0.001$ \\
\hline Active Motile & 32.75 & 58.75 & 26 & 79.38 & 9.38 & 2.098 & 12.3 & $<0.001$ \\
\hline Sluggish Motile & 32.25 & 51.5 & 19.25 & 59.78 & 5.93 & 1.33 & 10.33 & $<0.01$ \\
\hline Non-Motile & 36.75 & 24.75 & 12 & 32.65 & 5.104 & 1.14 & 9.2 & $<0.001$ \\
\hline
\end{tabular}

Table 3 Effect on various Sexual Parameters in 20 Subjects of Ksheena Shukra

\begin{tabular}{|c|c|c|c|c|c|c|c|c|}
\hline \multirow[t]{2}{*}{ Parameter } & \multicolumn{2}{|c|}{ Mean } & \multirow[t]{2}{*}{ Mean Diff. } & \multirow[t]{2}{*}{ Relief \% } & \multirow[t]{2}{*}{ S.D. } & \multirow[t]{2}{*}{ S.E. } & \multirow[t]{2}{*}{$\mathbf{t}$} & \multirow[t]{2}{*}{$\mathbf{p}$} \\
\hline & B.T. & A.T. & & & & & & \\
\hline Sexual desire & 2 & 3.1 & +1.1 & 87.87 & 0.763 & 0.171 & 8.47 & $<0.001$ \\
\hline Penile Erection & 1.95 & 3.35 & +1.4 & 71.79 & 0.882 & 0.20 & 7 & $<0.001$ \\
\hline Night Emission & 0.195 & 1.5 & +1.305 & 23.08 & 0.813 & 0.181 & 6.91 & $<0.001$ \\
\hline Post act exhaustion & 2.9 & 1.65 & 1.25 & 43.10 & 0.841 & 0.188 & 6.57 & $<0.001$ \\
\hline Dyspnoea on effort & 1.65 & 0.75 & -0.9 & 54.54 & 0.77 & 0.172 & 4.66 & $>0.01$ \\
\hline Pain during and after coitus & 1.9 & 0.75 & 1.15 & 60.52 & 0.68 & 0.152 & 7.57 & $<0.001$ \\
\hline
\end{tabular}

\section{Statistical analysis}

Statistical analysis of the study data was performed by an independent statistician using statistical software SPSS 10.0. Data describing quantitative measures were expressed as median or mean $\pm \mathrm{SD}$ or $\mathrm{SE}$ or the mean with range. All $P$ values are reported based on two-sided significance test and all the statistical tests were interpreted at 5\% level of significance.

\section{RESULT}

Of 20 patients included in the trial, all were completed the study. No patient was dropped out or withdrawn due to the adverse event or an adverse reaction. The highest incidence i.e. $12(60 \%)$ was seen in between 26-30 years of age, maximum incidence i.e. $06(30 \%)$ was in laborer and business man. $05(25 \%)$ patients were addicted to Alcohol, $09(45 \%)$ to Smoking and $13(65 \%)$ subjects were addicted to Tobacco chewing. Majority of the patients i.e. $06(30 \%)$ were reported for complaint of Oligozoospermia ranging between 5 to 6 years. $20 \%$ patients reported from 1 to 2 years. $03(15 \%)$ of patients had complaint since 7 to 8 years while $03(15 \%)$ of patients reported suffering from the disease for more than 08 years. The symptoms observed in different patients shows that the higher incidence was the symptom of post act exhaustion 17(85\%) and followed closely by psychological disturbance $15(75 \%)$. The lower incidence was the symptoms of night emission $02(10 \%)$. Other symptoms such as loss of libido $25 \%$, lack of erection $20 \%$ and painful ejaculation 07(35\%) were found. Beside these, complaints of pain in groin and testes, General weakness was also observed in the study.

Study treatment did not cause any significant change in vital signs like pulse rate, body temperature, respiratory rate, and the blood pressure. Changes observed after 90 days administration of Apatyakara Ghrita revealed following observations [Table $2 \& 3$ ]

- The patients showed $79.05 \%$ increase in volume statistically it was highly significant.
- The patients in sperm count showed $71.14 \%$ increase which is statistically highly significant result.

- The patients showed $79.05 \%$ increase in Active motile which is statistically highly significant.

- In sluggish motility of sperm the patients showed $59.78 \%$ increase in Active motile which is statistically highly significant.

- The patients showed $32.65 \%$ increase in non-motile statistically it was highly significant.

- There was an increase in sexual desire by $87.87 \%$ in patient which is statistically shows highly significant results.

- The penile erectile function was improved by $71.79 \%$ in registered patient which shows highly significant results.

- There was $23.08 \%$ relief in registered patient which shows statistically highly significant results in Night emission and Post act exhaustion was improved by 43.10 $\%$ in registered patient which shows highly significant results.

- There is relief of $54.54 \%$ in Dyspnoea on effort and $60.52 \%$ in Pain after and during coitus, both shows statistically highly significant results.

\section{DISCUSSION}

Several effective Vajikarana preparations are described in various Ayurvedic treatises which are known to cure problems regarding Ksheena Shukra and infertility. The drug - Apatyakar Ghrita mentioned in Charak Samhita was finalized for the present clinical trial which was said to be helpful in management of male infertility.

Apatyakara Ghrita was studied for its effect mainly on sperm count and motility in 20 cases of Oligozoospermia (Ksheena Shukra) to evaluate its effect on various parameters. The duration of Trial was 3 months and all the 20 subjects were followed up before and after the treatment to evaluate various changes produced by Apatyakara Ghrita. The observations made in the clinical study are summarized below: 


\section{Subjective Improvement}

All the 20 subjects registered were statistically assessed for the subjective improvement after the Apatyakar Ghrita therapy of 3 months. It was observed that patients treated with the Apatyakar Ghrita showed significant improvement $(p<0.05)$ in the subjects registered for the present trial after the therapy with Apatyakar Ghrita.

\section{Physiological Changes}

The influence of therapy given to the patients was assessed in terms of physiological changes in their Body Weight, Blood Pressure, Pulse Rate, Respiratory Rate and Temperature of the body of the patients.

The effect of Apatyakar Ghrita was also assessed on physiological parameters of Body weight, Blood pressure, pulse rate and respiratory rate. The statistical analysis of data reveals that the mean score rate in the final follow up study showed a statistically highly significant increase 2.36 $(p<0.001)$ was observed in the body weight of subjects after the therapy with Apatyakar Ghrita. In terms of percentage this increase is of $2.97 \%$. It is also seen that some patients have gained their weight after taking the Apatyakar Ghrita. It may be due to the Balya and Brimhana effect of the Shatavari as well as the ghrita.

The overall change in pulse rate is $5.86 \%$ which is statistically significant $(\mathrm{p}<0.01)$. Systolic Blood Pressure of the subjects has improved by $-9.2 \%$, which is statistically highly significant $(\mathrm{p}<0.001)$. Regarding the Diastolic Blood Pressure, the improvement noted is $4.16 \%$ which is statistically significant $(p<0.01)$. No significant change $(p>0.10)$ was observed in the Respiratory Rate of the subjects registered for the present trial after the therapy with Apatyakar Ghrita.

The improvement brought about in the physiological parameters is due to combined effect of individual constituents of Apatyakar Ghrita. As described earlier, a Vajikarana drug increases power in an individual; it also increases the body weight. The Drug Kapikacchu has been scientifically proved to increase muscle mass and strength by increasing the level of testosterone in the body.

\section{Changes in sexual parameters}

While assessing the effect of Apatyakar Ghrita on various Sexual parameters like Sexual desire, Night emission, Dyspnoea on effort, Post act exhaustion and Pain after and during coitus. It was observed that a highly significant improvement $(\mathrm{p}<0.001)$ occurred in Sexual desire and Night emission in the subjects registered for the present trial i.e. the Apatyakar Ghrita. In terms of percentage $87.87 \%$, and $23.08 \%$ improvement was observed in Sexual desire and Night emission respectively.

There was a highly significant improvement $71.79 \%$ seen in the penile erection in the subjects registered for the trial. Mean score rate in the final follow up study was markedly improved $(\mathrm{p}<0.001)$ in comparison to initial reading 60.52 and significant improvement $(\mathrm{p}<0.001)$ in pain after and during coitus in patient may because of Vidari kanda, Kaunch beej, and Vrihat Gokshura which have vrishya property. Since Vata is the controlling force for the erectile response and the rigidity is also, dependent and the Bala or strength of dhatus. The combined effect of the drugs in compound like vrisya, balya and vatahara actions may help in relief of the complaint.
In the parameters for Post act exhaustion and Dyspnoea on effort patients showed an improvement of $43.10 \%$ and $54.54 \%$ respectively. On all the two parameters, Shatavari and Vidari kanda have a better than Vajikar effect. Both the drugs are rasayana, Vrishya and have Brimhana action. Charak has mentioned Shatavari as balya. With the above action of the drugs the bala of the patient is increased and also the nutrition of the dhatus. This helps in over coming dourbalya and exertion related symptoms.

According to the statistical analysis of data recorded on the basis of observations and questioning, it is deduced that there was highly significant improvement in the patients of Oligozoospermia registered for the present trial.

\section{Seminal Changes}

Semen analysis was performed in all the subjects registered for the present trial to note any changes if occurred after the use of Apatyakar Ghrita.

Analysis done to note down any increase in the volume of semen ejaculated before and after the therapy in all 20 subjects. The volume of semen showed a trend of increase of $79.05 \%$ from the initial reading which showed statistically highly significant change $(\mathrm{p}<0.001)$

The sperm count showed a trend of increase of $71.14 \%$ from the initial reading which is statistically highly significant $(p<0.001)$ after treatment with Apatyakar Ghrita. The number of sluggishly motile sperms have decreased by $59.78 \%$ which is statistically significant $(\mathrm{p}<0.01)$. Highly significant decrease $(p<0.001)$ was observed in the number of nonmotile sperms which is $12 \%$ decrease from the original reading. The percentage increase in actively motile sperms is $79.38 \%$, which is also highly significant $(\mathrm{p}<0.001)$.

In addition to these, liquefaction time, viscosity and $\mathrm{pH}$ of all the samples of semen of the registered subjects were also conducted before and after the Apatyakar Ghrita Therapy. Liquefaction time was within 30 minutes in all the samples before and after the therapy. $\mathrm{pH}$ of all the samples was between 7.2 to 7.8 in all the collected samples. Viscosity was also normal in all samples in both the tests. Since Liquefaction time, $\mathrm{pH}$ and viscosity are within normal range before and after treatment therefore their calculation is not done statistically.

\section{REFERENCES}

1. S. C. Sikka, "Relative impacts of oxidative stress on male reproductive function," Current Medicinal Chemistry, vol. 8, no. 7, pp. 851-862, 2001.

2. A. Mahdi, F. Bano, R. Singh, R. K. Singh, M. S. Siddiqui, and M. Hasan, "Seminal plasma superoxide dismutase and catalase activities in infertile men," Journal of Medical Sciences Research, vol. 27, pp. 201203, 1999

3. Cooper TG, Noonan E, von Eckardstein S, et al. (2010). "World Health Organization reference values for human semen characteristics". Hum. Reprod. Update 16 (3):231-45.http://dx.doi.org/10.1093 /humupd/ dmp048 PMid: 19934213

4. Tripathi R, Shukla V, editor Vaidyamanorama hindi commentary. In charak samhita part $2,2^{\text {nd }}$ edition, Varanasi, India. Chaukhambha surabharati publication 2001 page 66 .

5. B K Ashok, A pharmaceutical comparison of guduchi ghrita prepared from male and female plants of tinospora cordifolia (willd.) Miers. Int. J. Res. Ayur Pharm. 20112 2(4) 1016-1019

6. Malik V. Editor Drugs \& Cosmetics Act commentatory, 1940, $18^{\text {th }}$ edition 2008 page 510 .

7. Trikamji Y editor Nibandhasangraha commentary. In Sushrut samhita. Varanasi, India. Chaukhambha Orientalia publications 1992 page 344.

Cite this article as:

Bagde A. B. A role of Apatyakara ghrita (An Ayurvedic formulation) in management of oligozoospermia. Int. Res. J. Pharm. 2013; 4(3):131-134 